\title{
Lesotho: Joint Staff Assessment of the Poverty Reduction Strategy Paper Status Report
}

The attached Joint Staff Assessment (JSA) of the Poverty Reduction Strategy Paper Status Report for Lesotho, prepared by the staffs of both the World Bank and IMF, was submitted with the member country's Poverty Reduction Strategy Paper Status Report (PRSP) to the Executive Boards of the two institutions. A JSA evaluates the strengths and weaknesses of a country's poverty reduction objectives and strategies, and considers whether the PRSP provides a sound basis for concessional assistance from the Bank and Fund, as well as for debt relief under the Enhanced Heavily Indebted Poor Countries (HIPC) Debt Initiative. The Boards then decide whether the poverty reduction strategy merits such support.

To assist the IMF in evaluating the publication policy, reader comments are invited and may be sent by e-mail to publicationpolicy@imf.org.

\author{
Copies of this report are available to the public from \\ International Monetary Fund • Publication Services \\ $70019^{\text {th }}$ Street, N.W. • Washington, D.C. 20431 \\ Telephone: (202) 623-7430 • Telefax: (202) 623-7201 \\ E-mail: publications@imf.org • Internet: http://www.imf.org
}

\section{International Monetary Fund Washington, D.C.}





\title{
INTERNATIONAL MONETARY FUND AND THE INTERNATIONAL DEVELOPMENT ASSOCIATION
}

\author{
LESOTHO \\ Joint Staff Assessment of the PRSP Preparation Status Report \\ Prepared by Staffs of the International Monetary Fund and \\ the International Development Association \\ Approved by Benedicte Vibe Christensen and Juha Kähkönen (IMF) \\ and Callisto Madavo and Gobind Nankani (IDA)
}

August 23, 2004

1. Lesotho's interim poverty reduction strategy paper (I-PRSP) was presented to the Executive Boards of the IDA and the IMF on March 6 and March 9, 2001, respectively. Progress towards the completion of the full PRSP has, however, been slow. The Boards of the IMF and IDA have considered two PRSP Preparation Status Reports, in March 2002 and April 2003, respectively. In both cases, the authorities indicated that the full PRSP would be completed within six months of these reports. However, for reasons outlined below, the full PRSP is now expected to be submitted to the IMF and the World Bank in mid-November, 2004. In view of the fact that more than a year has passed since the consideration of the second preparation status report by the two Boards, the authorities have prepared a third PRSP Preparation Status Report (hereinafter "the Report").

2. The Report states that the authorities are in the final stages of completing the PRSP and expect to submit it to Cabinet for approval by mid-October and to the Bank and the Fund by mid-November 2004. Consultations with community based working and thematic groups were concluded by mid-2003. Subsequently, over the past year the authorities carried out detailed exercises regarding costing, development of performance indicators, and document preparation. The costing exercise analyzed the proposed activities under each key component of the PRSP and compiled indicative cost estimates, allowing for a more direct linkage between the PRSP and the annual government budgets. The aggregate resource envelope was also updated, consistent with the medium-term fiscal strategy 2004/05-2006/07. In addition, a prioritization exercise was carried out to help identify the core activities to be included in the PRSP on the basis of their expected contribution to the country's development objectives and the expected resource constraints. In order to allow for performance monitoring under the PRSP, key performance indicators, baselines, and targets for 2006/07 were established.

3. The JSA of the I-PRSP noted that the I-PRSP was weak on sectoral policies for the medium to long term. It recommended that the Government should develop detailed reform strategies that would set clear priorities in the sectors, as well as provide for sequencing of policy measures and an indication of cost and financing. In preparing the PRSP, the 
authorities addressed this issue by developing sector policies and strategies for key sectors including health and social welfare, education and transport. In addition, the authorities have taken into consideration the analysis and findings from the Growth and Employment Options Study prepared by Bank staff in collaboration with the Government and other stakeholders. Furthermore, they have also made important progress towards finalizing the Household Budget Survey, a key input for the PRSP's poverty monitoring system, which is being developed with the support of UNDP and DFID. Data collection has been completed and the survey report is expected to be completed by the end of 2004. The Bank will, through the PRSP Trust Fund, provide support for the establishment and implementation of the monitoring system. Authorities are also developing a Public Sector Improvement Reform Program to be implemented within the civil service to strengthen the capacity for efficient service delivery. In the past year, findings of Lesotho's Diagnostic Trade Integration Study have also been incorporated in the PRSP to highlight the importance of Lesotho's integration in the world trading system, as a means for future growth and poverty alleviation. At the request of the Government, technical assistance was provided by the World Bank to support the preparation of the PRSP. Lesotho's key donor partners stationed in Lesotho have also provided financial and technical assistance to support the finalization of the PRSP.

4. The IMF and World Bank staffs acknowledge the considerable challenges involved in the preparation of the PRSP, and the serious capacity constraints that have contributed to the ongoing delays in completing the full PRSP. In addition to this, however, staffs are also of the view that the time table and action plan set out in the I-PRSP and subsequent status reports were too optimistic, and did not take into consideration the additional time required to secure the proper buy-in and support from the key policy makers and Cabinet. For example, the harmonization of the PRSP with the National Vision document, though a major source of delay, helped to improve public perception of the PRSP process, as well as reduce public confusion about the two initiatives. The staffs are of the view that the revised timetable for completing the PRSP is feasible, since document preparation is complete. However, it is considered ambitious because of the endorsements and approvals required from various groups and policy and decision makers. The authorities are encouraged to finalize the PRSP without further delay in order to help ensure access to Fund concessional lending. In addition, the World Bank would not be able to prepare a full Country Assistance Strategy to support the implementation of the government's PRS until the PRSP is received.

5. The staffs of the World Bank and IMF consider that progress on the development of the full PRSP, as evidenced by the PRSP Preparation Status Report, is satisfactory and provides a sound basis for continued access to current Fund concessional assistance and IDA adjustment lending. The staffs recommend that the respective Executive Directors of the World Bank and the IMF reach the same conclusion. 